\title{
Histórico, efeitos e mecanismo de ação do êxtase (3-4 metilenodioximetanfetamina): revisão da literatura
}

\author{
Stella Pereira de Almeida e Maria Teresa Araujo Silva ${ }^{1}$
}

RESUMO A presente revisão enfoca a 3-4 metilenodioximetanfetamina, droga ilegal conhecida como "êxtase". O êxtase foi introduzido no Brasil em 1994. Embora faltem dados sobre a epidemiologia e sobre os padrões de uso do êxtase no Brasil, há indicações de que o consumo seja, até o momento, restrito a jovens da classe alta ou média-alta e desconhecido para a maioria da população, inclusive para profissionais da saúde. Contudo, é possível que ocorra uma popularização dessa droga no Brasil, seguindo a tendência norte-americana e européia. A facilidade de consumo do êxtase - em forma de pilulas - pode ser um fator importante para sua popularização. O êxtase tem reputação de não apresentar perigo físico; contudo, há inúmeros relatos de reações adversas e mortes relacionadas à sua ingestão. Além disso, sabe-se que nem todos os comprimidos consumidos como êxtase necessariamente contém metilenodioximetanfetamina. Diante da ausência de controle farmacêutico, nenhum consumidor sabe exatamente o que está ingerindo. Assim, embora os efeitos do êxtase sejam percebidos como predominantemente positivos pelos usuários, a droga é potencialmente perigosa. Por essa razão, são necessárias intervenções de caráter primário e secundário para prevenir o uso de êxtase e a ocorrência de reações adversas. Para serem efetivas, tais ações devem levar em conta as características da população consumidora e seu padrão de consumo. Também é fundamental a capacitação de profissionais de saúde para intervenções médicas de emergência em casos de intoxicação e complicações resultantes do uso da droga.

O uso de drogas psicotrópicas é universal. É, ao mesmo tempo, primitivo e moderno; prejudicial, inócuo ou benéfico; singular, mas comum às mais diferentes culturas humanas em todos os tempos. Na cultura ocidental, as drogas de abuso, em particular as ilegais,

\footnotetext{
1 Universidade de São Paulo, Instituto de Psicologia, São Paulo, Brasil. Correspondência e pedidos de separatas devem ser enviados a Stella Pereira de Almeida no seguinte endereço: IPUSP, Departamento de Psicologia Experimental, Avenida Professor Mello Moraes 1721,CEP 15508-900, São Paulo, SP, Brasil. Telefone: +55-11-3818-4444 (ramal 208); e-mail: teresar@usp.br
}

são uma grande preocupação social. Entretanto, as ações que visam conter seu consumo por vezes exageram e por vezes negligenciam seu perigo físico e social.

A 3-4 metilenodioximetanfetamina (MDMA), conhecida como "êxtase", é uma droga psicotrópica ilegal produzida em laboratórios clandestinos. No Brasil, o êxtase também é conhecido como "E". Seu uso é bastante difundido nos Estados Unidos e na Europa, onde é conhecido como ecstasy, Adam (em referência a Adão, à inocência no paraíso antes do aparecimento da culpa e da vergonha), XTC ou E.
O êxtase é comercializado na forma de comprimidos ou cápsulas que custavam entre 25 e 45 reais (50 a 90 dólares) em julho de 2000 na Cidade de São Paulo. Sua via de administração mais comum é a oral, mas a droga também pode ser usada por via anal, ou pode ser macerada e aspirada. Vale ressaltar que a facilidade na forma de consumo do êxtase pode ser um fator importante para sua popularização. Enquanto as outras drogas ilegais tradicionais (com exceção do LSD) exigem um lugar reservado e, por vezes, um kit para confecção e consumo, o êxtase pode ser consumido com muita dis- 
crição em qualquer lugar e não exige nenhuma preparação. Além disso, em quantidade de uso individual, ou seja, até quatro comprimidos, o risco de ser identificado e apreendido pela polícia é mínimo.

O presente artigo apresenta uma revisão da literatura existente sobre o êxtase, subdividida nos seguintes tópicos: histórico, uso no Brasil, classificação e composição química, efeitos psicológicos e somáticos, toxicidade e complicações do uso e mecanismo de ação no sistema nervoso central.

\section{HISTÓRICO}

Há divergências quanto à data de síntese da MDMA: para alguns, a droga foi sintetizada em $1912(1,2)$; para outros, em $1914(3,4)$. De qualquer forma, foi patenteada em 1914 pelo laboratório Merck, na Alemanha. A MDMA foi testada inicialmente como moderador do apetite mas, devido a seus efeitos colaterais, foi pouco utilizada e nunca comercializada, ficando esquecida e sem uso por décadas. Em 1965, o bioquímico norteamericano Alexander Shulgin relatou ter produzido e consumido MDMA em seu laboratório, tendo descrito o efeito como prazeroso. Contudo, o bioquímico só voltou a se interessar pela droga no começo dos anos 70, quando tomou conhecimento de relatos de outros pesquisadores muito entusiasmados com o uso terapêutico da MDMA (4). A comunidade científica só veio a ser formalmente informada sobre a MDMA em 1978, através de uma publicação de Shulgin e Nichols, a qual sugere que a droga poderia ser utilizada como auxiliar psicoterapêutico (3).

Atualmente, o uso de drogas psicotrópicas alucinógenas como auxiliar psicoterapêutico é um episódio quase esquecido na história da psiquiatria e da psicologia. Hoje as drogas são utilizadas exclusivamente como tratamento químico, para aliviar ou curar sintomas. Entretanto, nas décadas de 50 e 60 , foram descritas inúmeras experiências bem sucedidas tendo o LSD como catalisador do processo terapêu- tico (5). Tais experiências não puderam prosseguir depois que essa droga passou a ser considerada ilegal.

Quando um novo tipo de tratamento medicamentoso é introduzido, é comum haver grande entusiasmo e alarde de sucessos, seguidos de desilusão advinda dos insucessos; a experiência de Freud com a cocaína (6) é um exemplo clássico. Entretanto, o ápice e o declínio das psicoterapias com uso de drogas alucinógenas têm algo de pouco comum, na medida que parecem ter sido banidas antes que insucessos ou prejuízos tivessem sido comprovados pela comunidade científica. O LSD cumpriu esse percurso, e a MDMA o sucedeu.

No início dos anos 70, a MDMA começou a ser utilizada em contexto terapêutico, como facilitador do tratamento. Apresentava vantagens sobre seu antecessor, o LSD, pois não provocava mudanças perceptivas nem emocionais tão intensas, seus efeitos tinham duração mais curta e não haviam sido relatados flashbacks, "más viagens" nem reações psicóticas em doses terapêuticas e em contextos controlados. Era utilizada como favorecedora da aliança terapêutica com o profissional na medida que aumentava a empatia, a confiança no terapeuta e a autoconfiança, convidando à auto-análise $\mathrm{e}$ favorecendo o insight (7).

Os primeiros psicoterapeutas a utilizar a MDMA perceberam sua potencialidade recreativa e conseqüente possibilidade de abuso e ilegalidade. Fizeram, então, um acordo, de desenvolver pesquisas informais sem chamar a atenção do público para a droga. Conseguiram fazê-lo durante um certo tempo, e o período entre 1977 e 1984 é considerado a "época de ouro" da pesquisa terapêutica com a MDMA (8).

Em 1984, final da "época de ouro", a MDMA não só era utilizada como auxiliar terapêutico, mas também estava sendo amplamente utilizada pelos jovens norte-americanos como droga recreativa. Uma pesquisa realizada em 1986 na Universidade de Tulane, Estados Unidos, constatou que $15 \%$ dos estudantes haviam experimentado êxtase pelo menos uma vez na vida (9). Em outra pesquisa, realizada também em 1986, na Universidade de Stanford, Estados Unidos, 39\% dos estudantes declararam ter consumido êxtase pelo menos uma vez na vida (10). Nessa época, a MDMA já era denominada êxtase, valendo ressaltar o forte apelo mercadológico do nome, e era vendida livremente em bares que aceitavam cartões de crédito (8). Esse uso público, livre e crescente chamou a atenção da imprensa que, em 1985, publicou matérias de capa em várias revistas, como Newsweek, Time e Life (11-13). A visibilidade na mídia atraiu mais adeptos e disseminou o uso antes restrito a determinadas cidades norte-americanas (14). Além disso, também em 1985, divulgou-se que o uso de uma outra droga sintética, chamada China white, sintetizada com o intuito de substituir a heroína, causara graves danos cerebrais em usuários. Comentando o fato, os meios de comunicação sugeriram que o êxtase seria uma droga similar à China white, o que o transformou em neurotóxico potencial e, portanto, em problema de saúde pública. Por fim, foi publicado um relatório no qual eram apresentadas evidências de danos cerebrais causados pela MDA (metilenodioxianfetamina), droga análoga à MDMA, em ratos (8).

Assim, a popularização do uso de MDMA, a publicidade nos meios de comunicação, o incidente China white e a publicação do artigo sobre o potencial neurotóxico de seu análogo MDA encerraram a fase de uso legal de êxtase. Em maio de 1985, a agência de controle de drogas (Drug Enforcement Administration, DEA) dos Estados Unidos convocou uma comissão de emergência para enquadrar a MDMA na categoria 1 de substâncias controladas, que inclui drogas a) com alto potencial de abuso; b) sem benefício terapêutico/médico; e c) cujo uso é inseguro mesmo sob supervisão médica (15). Em junho de 1986, audiências decidiram manter o caráter de ilegalidade da droga e seu enquadramento na categoria 1, ainda que psicólogos e psiquiatras tivessem testemunhado a favor do uso da MDMA como auxiliar do processo psicoterapêutico (7). 
Na Europa, a MDMA sempre foi ilegal. Seu consumo foi introduzido com fins espirituais por discípulos de Bhagwan Rajneesh, em meados da década de 80. Contudo, foi a partir de um evento musical acontecido em Ibiza, Espanha, entre 1987 e 1988, no qual muitos participantes experimentaram a MDMA, que surgiram as festas conhecidas como raves. Com elas, o uso do êxtase se popularizou na Europa. Quando o evento musical terminou, os jovens voltaram para seus países com o desejo de perpetuar a experiência. Alguns empresários ingleses perceberam que recriar a atmosfera de Ibiza seria muito bem aceito. Começaram a organizar festas em armazéns portuários londrinos, onde centenas de pessoas pagavam um ingresso e dançavam a noite inteira com música eletrônica ininterrupta, usando êxtase ou, na sua falta, LSD. Essas festas ganharam cada vez mais adeptos e começaram a acontecer em locais maiores, fora do perímetro urbano, mas perto de Londres. Logicamente, as festas que reuniam centenas ou milhares de jovens dançando a noite inteira e usando drogas atraíram a atenção da polícia e, em 1990, foi aprovada, no Reino Unido, uma lei que previa pena de até 6 meses de detenção e confisco de todo o lucro para organizadores de festas rave. Com isso, os empresários desistiram de organizar as festas e os ravers se deslocaram para os clubes noturnos. A partir daí, o êxtase passou a fazer parte da cultura dance-clubber (8). Nos Estados Unidos, as raves surgiram no início dos anos 90 e, assim como na Europa, o uso de êxtase faz parte da festa (4). Ao longo desses 10 anos, as raves vêm se espalhando pelos Estados Unidos.

A ilegalidade da MDMA não parece ter diminuído o número de usuários recreativos que, ao contrário, só tem aumentado, como demonstram vários levantamentos realizados tanto na Europa como nos Estados Unidos $(9,16)$. Além disso, embora a ilegalidade tenha encerrado o uso terapêutico da MDMA, ainda se afirma que seriam necessárias mais pesquisas para descartar seu uso na medicina psiquiátrica (17). Até hoje há grupos que defendem a legalização da MDMA Recentemente foi aprovado o primeiro estudo sobre seu uso terapêutico, em pesquisa que será desenvolvida na Espanha (18).

\section{Uso no Brasil}

As primeiras remessas significativas de êxtase chegaram a São Paulo em 1994, vindas principalmente de Amsterdã, Holanda. Naquele momento ainda não havia tráfico de êxtase; algumas pessoas traziam os comprimidos $\mathrm{e}$ os revendiam seletivamente a amigos em clubes noturnos (19). Se na Europa o consumo de êxtase começou nas raves e depois foi para os clubes, em São Paulo seu percurso foi inverso. As raves, organizadas por $D J s$ brasileiros vindos de Londres, apareceram em 1995 depois da introdução da droga em clubes noturnos. Nessa época, as festas eram realizadas cada 2 ou 3 meses com um público menor e menos heterogêneo do que hoje. Atualmente, em São Paulo, há festas-rave todos os finais de semana em lugares amplos e ao ar livre, tais como praias, sítios ou parques aquáticos. Reúnem de 3 a 5 mil pessoas e duram de 14 a 18 horas. A música eletrônica é ininterrupta; o ambiente é decorado com panos fluorescentes, com motivos tântricos ou alienígenas, e a iluminação é feita com luzes negras, coloridas, estroboscópicas, laser e globos de espelhos. As várias pistas de dança são comandadas por DJs que ocupam o lugar de maior status nas festas, já que a motivação comum é dançar. Os participantes ou ravers se vestem em geral com roupas coloridas, usam adereços fluorescentes, valorizam moda e bodyart, que inclui tatuagens e aplicação de adereços no corpo (piercing). É inegável a presença de êxtase nas raves e grande parte de seus usuários estão ali concentrados. Outra parte dos usuários (por vezes sobreposta aos ravers) são os clubbers, indivíduos que freqüentam casas noturnas onde também se dança a noite inteira com música eletrônica ininterrupta comandada por DJs. A moda é também extremamente valorizada, mas aqui menos colorida e psi- codélica, mais geométrica e tecnológica. Tatuagens e piercings também fazem parte da cultura clubber. Ambos os grupos pertencem, na sua maioria, à classe alta e média alta e têm bom nível educacional, até porque esse estilo de vida não é barato.

Na mídia brasileira, a visibilidade do êxtase vem aumentando. Até 1999, era citado poucas vezes, grafado em inglês (ecstasy), quase sempre nos cadernos de cultura, em matérias ligadas à moda ou comportamento, como signo de grupos ou tendências de vanguarda, sem informações sobre a droga. Vale citar que, em junho de 1999, a revista Veja-São Paulo (encarte de publicação semanal distribuído exclusivamente na cidade da São Paulo com tiragem de 370000 exemplares) publicou uma matéria de capa sobre raves, na qual, curiosamente, o êxtase não é citado (20). Atualmente, o êxtase é cada vez mais citado nas páginas policiais, com notícias de um crescente número de prisões e apreensões. Em setembro de 2000 foi noticiada a descoberta do primeiro laboratório de êxtase em São Paulo (21).

\section{CLASSIFICAÇ̃̃O E COMPOSIÇÃOO QUÍMICA}

De acordo com o efeito provocado no sistema nervoso central, as drogas psicotrópicas podem ser classificadas como estimulantes, depressoras ou perturbadoras de seu funcionamento. As drogas perturbadoras são também chamadas alucinógenas. Com relação ao seu efeito, a MDMA é uma das poucas drogas com dupla classificação: situa-se entre os estimulantes e os alucinógenos, sendo por vezes classificada como uma anfetamina alucinógena (3).

A MDMA é freqüentemente classificada como droga de desenho, termo com dois significados: primeiro, o termo se refere a qualquer substância fabricada para produzir efeitos específicos, definição pouco elucidativa e muito geral, na qual poderiam enquadrar-se inúmeras substâncias; segundo, o termo se refere a drogas análogas a substâncias ilegais e com 
efeitos psicológicos semelhantes, produzidas através de processo de engenharia química, com o objetivo de esquivar-se do controle legal (14). Por ser análoga à anfetamina e à metanfetamina, a MDMA é, às vezes, considerada droga de desenho; entretanto ela foi patenteada em 1914, muito antes, portanto, de tornar-se ilegal nos Estados Unidos, em 1970. Assim, embora alguns autores definam a MDMA como uma droga de desenho, essa classificação não está bem aplicada $(14,22,23)$.

Dada a dificuldade de enquadrar a MDMA na classificação habitual das drogas psicotrópicas, foi proposto um termo bastante específico que descreveria os efeitos da MDMA e de seus análogos: entactogen. O termo é usado para drogas cujos efeitos são o aumento de contato do usuário consigo mesmo e da introspeção, aumento da empatia e da comunicação com outras pessoas, indução a estado positivo de humor, sentimentos de intimidade e tranqüilidade (4). Esse termo não vingou, mesmo porque estava ligado às experiências terapêuticas com a MDMA, encerradas com sua proibição.

A MDMA é produzida sinteticamente em laboratório a partir de metanfetamina. Porém, há precursores químicos naturais contidos em óleos de plantas, como noz moscada, endro, cálamo, açafrão, canela e semente de salsa (24). Sua estrutura química é apresentada na figura 1 .

Dada sua ilegalidade, sabe-se que nem todos os comprimidos vendidos e consumidos como êxtase necessariamente contém MDMA. O êxtase é uma droga sem nenhum controle farmacêutico. Ninguém sabe exatamente o que está ingerindo; o controle "farmacológico" é feito por usuários que já usaram um determinado tipo de êxtase e aprovaram ou não seus efeitos. Os tipos de êxtase ganham apelidos conforme a cor e o desenho impresso nos comprimidos e sua popularidade e preço variam de acordo com os efeitos produzidos. No Brasil, os tipos disponíveis mudam conforme a chegada de importações. Segundo relatos informais de usuários, grande parte do êx- tase consumido no Brasil vem da Europa e, em julho de 1999, os tipos mais comuns em São Paulo eram o "JB amarelo", o "mitsubishi" e o "verde RN".

Em 1995, foram realizadas análises nos comprimidos de êxtase mais consumidos no Reino Unido. Os resultados mostraram que a maioria contém uma mistura de MDMA com uma ou mais drogas em proporções variadas, e que alguns nem sequer contêm MDMA. As outras drogas mais freqüentemente associadas à MDMA nos comprimidos de êxtase foram: metilenodioxietanfetamina (MDEA, análogo sintético da MDMA), metanfetamina, anfetamina, paracetamol, cafeína ou ketamina (25). Entretanto, outras pesquisas averiguaram que o êxtase é pouco adulterado na Austrália e na Europa, sendo que quando não é puro, contém uma mistura de MDMA com seu análogo MDA (26). Embora esses dados justifiquem a consonância dos efeitos relatados por usuários de êxtase de diversos países, é importante salientar que essas pesquisas foram realizadas ainda na década de 80 e que, portanto, esse quadro pode ter mudado; nesse caso, a pesquisa realizada por Wolff et al., em 1995 (25), talvez traduza melhor o quadro da composição dos comprimidos hoje em dia. De qualquer forma, o fato é que só uma análise em amostras comercializadas atualmente nos diria se o que é usado como êxtase é, de fato, MDMA. Enquanto isso, o conteúdo dos comprimidos consumidos no Brasil é duvidoso e desconhecido.

\section{EFEITOS PSICOLÓGICOS E SOMÁTICOS}

Os efeitos da MDMA se fazem sentir aproximadamente 20 minutos após a ingestão do comprimido e permanecem por 4 a 8 horas (22). Os vários estudos sobre os efeitos provocados pelo êxtase apresentam resultados muito semelhantes (26-29). Os efeitos agudos são descritos na maioria das vezes como prazerosos, embora também sejam apontados efeitos desagradáveis, quase sempre físicos. Já os efeitos
FIGURA 1. Estrutura química do êxtase (3, 4 metilenodioximetanfetamina)

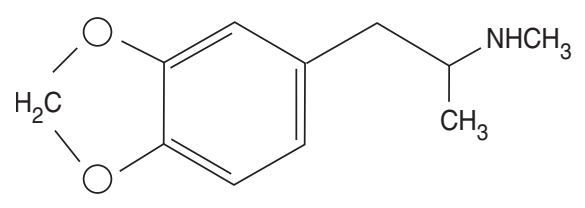

24 horas após a ingestão são descritos como mais negativos, tanto física quanto psicologicamente. Os efeitos de curto e longo prazo descritos pelos vários pesquisadores estão reunidos na tabela 1 .

\section{TOXICIDADE E COMPLICAÇÕES DO USO DE MDMA}

Embora a MDMA tenha reputação de droga segura, ou seja, que não apresenta perigo físico (4), há inúmeros relatos de reações adversas e mortes relacionadas à sua ingestão $(30,31)$. Para alguns autores, ainda não há provas de que a MDMA deixe seqüelas severas em seres humanos e, a despeito dos relatos de efeitos adversos agudos, o números de casos é surpreendentemente pequeno em relação ao número de usuários $(32,33)$.

Há dois problemas principais relativos à segurança ou perigo da MDMA. Um deles é a incerteza da composição dos comprimidos. O outro é a mistura que freqüentemente os usuários fazem com outras drogas, como outros estimulantes, opiáceos e álcool. Não há dúvida de que essas duas questões estão diretamente relacionadas ao aumento do potencial de perigo, toxicidade e risco de efeitos adversos agudos relacionados à MDMA. Também é importante salientar que a toxicidade de qualquer droga é dependente da dose, da freqüência de uso, da vulnerabilidade individual e das condições externas ambientais (34).

Vale ainda salientar que os padrões de uso de êxtase mudaram muito desde o início de sua utilização com fins terapêuticos e mesmo recreativos nos Estados Unidos. Da utilização em 
TABELA 1. Efeitos imediatos e tardios do êxtase de acordo com diversos estudos ${ }^{a}$

\begin{tabular}{|c|c|c|}
\hline & \multicolumn{2}{|c|}{ Efeitos } \\
\hline & Psicológicos & Somáticos \\
\hline $\begin{array}{c}\text { Imediatos } \\
\text { (4-8 } \\
\text { horas) }\end{array}$ & $\begin{array}{l}\text { Loquacidade } \\
\text { Abertura mental } \\
\text { Proximidade de outras pessoas } \\
\text { Felicidade } \\
\text { Bom humor } \\
\text { Sensualidade } \\
\text { Euforia } \\
\text { Aumento da autoconfiança } \\
\text { Despreocupação } \\
\text { Aumento de energia } \\
\text { Excitabilidade sexual } \\
\text { Leve sensação de desrealização }\end{array}$ & $\begin{array}{l}\text { Depressão } \\
\text { Despersonalização } \\
\text { Flashbacks } \\
\text { Preocupação } \\
\text { Insônia } \\
\text { Dificuldade de concentração }\end{array}$ \\
\hline $\begin{array}{l}\text { Tardios } \\
\text { (24 horas) }\end{array}$ & $\begin{array}{l}\text { Inapetência } \\
\text { Boca seca } \\
\text { Agitação } \\
\text { Aceleração do batimento cardíaco } \\
\text { Bruxismo/trismo } \\
\text { Insônia } \\
\text { Fluxos de frio e calor } \\
\text { Sudorese } \\
\text { Dificuldade de concentração } \\
\text { Vontade de urinar } \\
\text { Midríase } \\
\text { Náusea } \\
\text { Ataxia (descoordenação motora) }\end{array}$ & $\begin{array}{l}\text { Inapetência } \\
\text { Sede } \\
\text { Falta de energia } \\
\text { Fadiga } \\
\text { Tontura } \\
\text { Dores musculares }\end{array}$ \\
\hline
\end{tabular}

a Baseado em Cook (22), Solowij et al. (26), Cohen (27), Ferigolo et al. (28) e Vollenweider et al. (29).

isolamento ou em pequenos grupos de amigos, em festas ou reuniões para poucas pessoas, passou a ser usado em clubes ou raves. Como já foi observado, esses locais são espaços para se dançar muitas horas seguidas, com música eletrônica muito alta e ininterrupta, lugares com centenas e por vezes milhares de pessoas, com temperatura elevada e ventilação nem sempre adequada. Pode-se bem supor que essa mudança no ambiente de uso de êxtase esteja associada ao aumento no número de casos de mortes e intoxicações. De fato, o fenômeno da toxicidade anfetamínica de agrupamento foi demonstrado em ratos. Isso significa que tanto os efeitos comportamentais quanto os efeitos tóxicos da anfetamina aumentam quando os animais são agrupados em relação a quando estão isolados. Mesmo quando a área total por animal é a mesma, observouse um aumento da toxicidade anfetamínica em condições de agrupamento e temperaturas mais altas. Além disso, também se observou que, para animais colocados em caixas individuais, a toxicidade é diretamente proporcional à temperatura ambiente e ao ruído externo, e inversamente proporcional à hidratação. Essas constatações podem ser relevantes para o estudo da toxicidade da MDMA, já que seu uso em raves e clubes apresenta as características de propensão a maior toxicidade, ao menos por analogia à anfetamina (35).

De qualquer forma, já foram descritos diversos problemas relacionados à administração de MDMA. Os sintomas de intoxicação aguda, as manifestações psicológicas e/ou comportamentais e as complicações orgânicas já relacionados ao uso de MDMA são apresentados na tabela 2 (36).

Dentre as complicações clínicas, a hipertermia é a ocorrência mais freqüente associada à MDMA, quadro no qual os usuários podem chegar a tem- peraturas corporais de $42^{\circ} \mathrm{C}$. A razão pela qual a MDMA afeta a termorregulação corporal não é clara, mas parece estar relacionada com o aumento de liberação de serotonina. As condições externas habitualmente associadas ao uso de êxtase, ou seja, exercício físico intenso em ambiente quente e falta de hidratação, aumentam consideravelmente o risco de hipertermia. A hipertermia pode causar desidratação, queda de proteínas musculares, rabdomiólise, coagulação intravascular disseminada (DIC), convulsões e morte. Até 1994, haviam sido relatados 26 casos de hipertermia na Inglaterra, dos quais nove foram letais (30). Para combater o risco amplamente divulgado de desidratação, os usuários costumam beber grandes quantidades de água (está descrito um caso de morte após ingestão de 13 litros), cujos efeitos podem ser hipotermia (37) e edema cerebral (38).

Também estão documentados vários casos de problemas hepáticos relacionados ao uso de MDMA, desde icterícia até insuficiencia renal aguda com necessidade de transplante (30). O mecanismo pelo qual a MDMA ocasiona problemas hepáticos ainda não está claramente definido, mas parece ser uma reação idiossincrática, pois independe da dose e da freqüência de uso e pode ocorrer tanto após o primeiro quanto após vários episódios de uso de MDMA (39). Foi registrado um caso de retenção urinária após ingestão de grande quantidade de MDMA (15 comprimidos em 36 horas), efeito provavelmente devido à ação agonista alfa adrenérgica da MDMA (40).

Em relação a problemas psiquiátricos, ainda é pouco conhecida a morbidade psiquiátrica associada ao uso de êxtase. Entretanto, há vários casos documentados, mais freqüentemente psicoses e psicoses paranóicas $(31,32)$. Foram também descritos três casos de ataque de pânico. Esses quadros se iniciaram 30 minutos após a ingestão e tiveram uma duração limitada. Em dois dos casos relatados houve remissão sem uso de medicamentos. Um deles recorreu a um pronto socorro, onde 
TABELA 2. Sintomas de intoxicação aguda, manifestações psicológicas e comportamentais e complicações orgânicas associados ao consumo do êxtase ${ }^{a}$

\begin{tabular}{lll}
\hline \multicolumn{1}{c}{$\begin{array}{c}\text { Intoxicação } \\
\text { aguda }\end{array}$} & \multicolumn{1}{c}{$\begin{array}{c}\text { Manifestações } \\
\text { psicológicas e } \\
\text { comportamentais }\end{array}$} & \multicolumn{1}{c}{$\begin{array}{c}\text { Complicações } \\
\text { orgânicas }\end{array}$} \\
\hline $\begin{array}{l}\text { Dilatação da pupila } \\
\text { Cefaléia }\end{array}$ & Ansiedade & Insuficiência renal aguda \\
Nistagmo & Ataques de pânico & Hemorragia \\
Dispnéia & Desorientação & Convulsão/crise epiléptica \\
Náusea/vômitos & Psicose & Hepatite \\
Taquicardia & Paranóia & Rabdomiólise \\
Visão turva & Depressão & Hipertermia \\
Problemas renais & Alucinações & Hipertensão \\
Bruxismo/trismo & Idéias suicidas & Hemorragia cerebral \\
Tensão muscular & Flutuação de humor & Incontinência \\
Transpiração & Estupor catatônico & Coma \\
& Despersonalização & Coagulação intravascular \\
Falta de salivação & disseminada \\
\hline
\end{tabular}

a Baseado em Bailly (49).

foi medicado. O quadro não voltou a ocorrer mesmo nos indivíduos que usaram êxtase novamente após o incidente (41). Há casos em que o uso de êxtase está associado à ideação suicida e ao suicídio. Embora esteja comprovado que há uma correlação entre os baixos níveis de ácido 5-hidroxi-indolacético (5-HIAA) cérebro-espinhal e o suicídio, e que a MDMA causa esgotamento cerebral de serotonina (5-HT) e de seu metabólito 5-HIAA, não se pode concluir que a MDMA seja a única responsável pelo desencadeamento da ideação suicida ou do suicídio (42).

Embora a MDMA seja geralmente descrita como uma droga que não causa dependência, foram descritos casos clínicos que preenchem os critérios de síndrome de dependência (43). Um experimento realizado com babuínos mostrou que a MDMA age como reforçador, resultado que sugere potencial de abuso (44).

O desenvolvimento da tolerância decorrente do uso freqüente de MDMA não se dá de forma homogênea para todos os sintomas. Com o uso habitual, a intensidade dos efeitos colaterais indesejáveis, tais como inapetência, trismo, náusea, dores musculares, ataxia, sudorese, taquicardia, fadiga e insônia aumentam, enquanto diminuem os efeitos subjetivos prazerosos, como melhora do humor e alucinações (26). Por isso, é comum os usuários fazerem pausas de abstinência, retomando o uso após algumas semanas, a fim de recuperar os efeitos positivos anteriores ao estabelecimento de tolerância.

Em relação às funções cognitivas, um dos estudos realizados com usuários crônicos de êxtase não encontrou outros prejuízos cognitivos a não ser prejuízos de memória e atenção (45). Em ratos, embora a MDMA tenha causado redução dos níveis de 5-HT cerebral, a memória não é afetada (46). Mas, segundo o Instituto Nacional de Abuso de Drogas (National Institute on Drug Abuse, NIDA), nos Estados Unidos, um estudo comparativo entre não usuários e usuários habituais indicou prejuízos significativos de memória verbal e visual entre usuários habituais. Os prejuízos foram diretamente proporcionais à dose e continuaram no mínimo 2 semanas após a interrupção do uso. Isso parece estar relacionado a danos causados aos neurônios serotonérgicos (47). Ainda com relação à memória, foi descrito um caso de síndrome amnésica em decorrência da ingestão de êxtase. Após 9 meses, a paciente ainda apresentava pequeno prejuízo de memória (48).

Também foi observado que o uso de êxtase afeta o sono dos usuários. Foram comparados os tempos totais de sono de usuários (mais de 25 episódios de uso) e de indivíduos que nunca haviam usado êxtase. Os sujeitos de ambos os grupos não usavam drogas psicotrópicas há 2 semanas. Constatou-se que os usuários tinham menos tempo total de sono do que os não usuários, e que essa diferença se devia a um menor tempo de sono nãoREM entre os usuários. Embora não se saiba se essa alteração se deve à toxicidade serotonérgica da MDMA, os dados sugerem que a MDMA pode causar mudanças persistentes em estruturas cerebrais ligadas ao sono (49). Também são relatados outros efeitos sobre o sono de usuários de êxtase: insônia, inversão do ritmo vigília/ sono, pesadelos, alucinações hipnagógicas e bruxismo (36).

Foi demonstrado que usuários de êxtase apresentam desgaste dos dentes significativamente maior do que não usuários. Esse desgaste é atribuído ao bruxismo provocado pela droga. O desgaste dentário é ainda exacerbado quando o êxtase é associado à ingestão de bebidas gasosas, o que ocorre freqüentemente (50). São ainda relatados problemas dermatológicos e emagrecimento em usuários habituais de êxtase.

$\mathrm{O}$ uso de êxtase por gestantes está associado a um aumento de máformações congênitas, predominantemente anomalias cardiovasculares e musculoesqueléticas (51). Por último, parece que a MDMA deprime o sistema imunitário, em especial quando associada ao álcool. Entretanto, essa observação foi feita em pesquisa realizada com um pequeno número de sujeitos, o que significa que amostras maiores seriam necessárias para comprovar tal ação (52).

\section{MECANISMO DE AÇÃO NO SISTEMA NERVOSO CENTRAL}

A administração de MDMA em animais desencadeia uma resposta bifásica que pode ser dividida em efeitos de curto prazo (primeiras 24 horas) e de longo prazo (que permanecem após 24 horas, podendo durar até mais de 
12 meses). Os efeitos psicológicos e comportamentais de curto prazo parecem estar mais diretamente ligados à estimulação serotonérgica, enquanto os efeitos de longo prazo estão mais relacionados ao desenvolvimento de neurotoxicidade serotonérgica (53).

\section{Efeitos de curto prazo}

O primeiro efeito de curto prazo é a ação sobre a 5-HT e seu metabólito 5HIAA. A MDMA promove a liberação de 5-HT, sendo um agonista serotonérgico indireto. A MDMA atravessa rapidamente a membrana pré-sináptica; ainda não se sabe se isso se dá passivamente ou através de um transportador. Após atravessar a membrana, a MDMA causa efluxo de 5-HT da vesícula para o citoplasma do neurônio. Do citoplasma da célula nervosa, a 5HT é rapidamente liberada para o espaço extracelular através de transportadores serotonérgicos. A liberação de 5-HT induzida pela MDMA pode ser bloqueada por inibidores da recaptação de serotonina, por exemplo, a fluoxetina $(34,54)$.

Essa observação sugere duas hipóteses: a primeira é que a MDMA é transportada passivamente para dentro da célula nervosa, desencadeando a liberação de 5-HT vesicular para o citoplasma; nesse caso, a fluoxetina bloquearia os transportadores, impedindo a liberação de 5-HT citoplasmática na fenda. Uma segunda hipótese seria que a passagem da MDMA através da membrana necessita de um transportador e nesse caso a fluoxetina, bloqueando o transportador, impediria que a MDMA atravessasse a membrana e promovesse a liberação de 5-HT da vesícula para o citoplasma (54).

Além de promover a liberação de 5HT, estudos in vitro mostraram que a MDMA tem capacidade de inibir sua recaptação pelos terminais nervosos. In vivo, parece que a MDMA também tem ação inibitória sobre os transportadores responsáveis pela recaptação de 5-HT. O bloqueio de recaptação de 5-HT prolongaria as ações pré e pós- sinápticas da liberação de 5-HT, aumentando efetivamente sua concentração na fenda sináptica (54). A MDMA também provoca decréscimo na atividade da enzima triptofano-hidroxilase (TPH), responsável pela síntese de 5HT (53). O mecanismo preciso através do qual a MDMA interfere na atividade da TPH é desconhecido. Uma hipótese é que, direta ou indiretamente, a MDMA tenha um efeito oxidativo nos terminais nervosos, o que pode desativar a TPH (54). A liberação maciça de 5-HT, somada ao bloqueio de sua recaptação e à desativação da $\mathrm{TPH}$, resulta no esgotamento intraneuronal de 5-HT. Após uma única dose de MDMA o esgotamento de 5-HT é rápido, ocorrendo entre 1 e 3 horas após sua administração. Em ratos, as reduções na concentração de 5-HT e de seu metabólito chegam a $80 \%$ em 3 horas (53).

Cabe notar ainda que a MDMA tem grande afinidade pelo sub-receptor serotonérgico $5-\mathrm{HT}_{2}$, considerado responsável pelos efeitos alucinógenos causados pelo LSD. Isso sugere que a ligação da MDMA a esse receptor modula os efeitos alucinógenos atribuídos a ela.

Outro efeito de curto prazo é a ação da MDMA sobre a dopamina (DA), noradrenalina (NA) e receptores de outros neurotransmissores. Em contraste com a acentuada redução intracelular de 5-HT, conseqüente à administração de MDMA, não foram observadas mudanças similares nos níveis de DA ou NA (53). In vitro, demonstrou-se que a MDMA bloqueia a recaptação de DA e NA, embora tenha baixa afinidade pelo transportador dopaminérgico.

In vivo, há poucas evidências sugerindo que a MDMA cause, diretamente, liberação de DA na maioria das regiões cerebrais (54). Uma pesquisa mais recente descreve que a MDMA estimula a liberação de DA em sinapses dopaminérgicas (34); segundo os autores, parece que a MDMA ultrapassa a membrana pré-sináptica através de um processo passivo, causando a liberação de DA vesicular através de um mecanismo similar ao que ocorre nos neurônios serotonérgicos. O transporte da DA citoplasmática livre para a fenda sináptica é mediado por transportadores dopaminérgicos da membrana. Ainda segundo esses autores, a ativação dos receptores $5 \mathrm{HT}_{2 \mathrm{~A}^{\prime}}$ através da liberação de 5-HT, parece facilitar a liberação de DA induzida pela anfetamina, enquanto a administração de antagonistas de $5-\mathrm{HT}_{2 \mathrm{~A}}$ atenua os efeitos de análogos anfetamínicos (como por exemplo, a MDMA) sobre a liberação de DA. É bem possível que a MDMA ocasione a liberação de NA em terminais noradrenégicos através de um mecanismo similar ao da liberação de DA, mas esse efeito ainda não foi investigado.

A interação com o receptor alfa-2 adrenérgico deve ser relevante para os efeitos cardiovasculares, ou seja, aumento do batimento cardíaco, hipertensão e arritmias. Além da afinidade da MDMA pelo transportador de 5-HT e pelo receptor alfa-2 adrenérgico, a MDMA também tem afinidade pelo receptor colinérgico muscarínico $\mathrm{M}_{1} \mathrm{e}$ pelo receptor histamínico $\mathrm{H}_{1}$ (54). Um estudo mais recente demonstrou, em fatias de cérebro de rato, que a MDMA promove a liberação de acetilcolina no estriado e que essa liberação é abolida por antagonistas $\mathrm{H}_{1}$. Ainda segundo o mesmo estudo, a ativação direta do receptor $H_{1}$ poderia representar um mecanismo plausível para a liberação de acetilcolina induzida pela MDMA (55). A intoxicação aguda de MDMA ainda espera caracterização farmacológica mais detalhada (55).

\section{Efeitos de longo prazo}

O primeiro efeito de longo prazo envolve os níveis cerebrais de 5-HT e de seu metabólito 5-HIAA. Vários pesquisadores descreveram que a MDMA é responsável por reduções duradouras nos níveis cerebrais de 5-HT e 5HIAA, em alguns casos persistindo por mais de 12 meses $(35,53,54)$. Também a diminuição da atividade da TPH em conseqüência da administração de MDMA é duradoura. Esse dado indica a potencialidade neurotó- 
xica da MDMA. A atividade cortical da TPH permanece significativamente reduzida 1 semana após sua administração, o que indica a irreversibilidade da desativação da TPH pela MDMA, de forma que seu restabelecimento depende da síntese de nova enzima (35).

Estudos in vitro e in vivo constataram que a administração crônica de MDMA causa diminuição na densidade de receptores 5-HT em ratos. Em seres humanos também foi observada diminuição na densidade de receptores 5-HT em usuários crônicos de MDMA (56). Entretanto, há várias críticas a essa pesquisa humana no que diz respeito ao método, tanto em relação à amostra quanto à técnica empregada (57-59).

\section{CONCLUSÕES}

Há uma absoluta falta de dados epidemiológicos brasileiros sobre o consumo de êxtase, e não há publicações sobre seu padrão de uso em nenhuma cidade do Brasil até o presente momento. Nos quatro levantamentos nacionais sobre consumo de drogas, realizados em 1987, 1989, 1995 e 1997, não consta nenhuma questão sobre o êxtase como uma das drogas já utilizadas na vida (60-63). O consumo de êxtase no Brasil é, por enquanto, restrito a determinado grupo e desconhecido para a maior parte da população. Entretanto, esse consumo vem provavelmente aumentando, podendo acabar por seguir a tendência norte-americana e européia.

Segundo o Departamento de Inteligência e Apoio à Polícia (DIAP), divisão do Departamento de Narcóticos (DENARC) do Estado de São Paulo, foram apreendidos em São Paulo 1140 comprimidos de êxtase em 1998, nove comprimidos em 1999 e 613 até junho de 2000. As apreensões de êxtase podem não estar diretamente relacionadas ao consumo. É possível que a estratificação social do uso de êxtase e seu desconhecimento pela maioria da população determine pouco interesse, seja da sociedade, seja do governo, por uma repressão mais efetiva. Assim, à medida que cresce o interesse e a vei- culação de reportagens sobre o assunto, é de se supor que também sejam realizadas maiores apreensões.

É fundamental a capacitação de profissionais de saúde para intervenções médicas de emergência em casos de intoxicação e complicações do uso. A intervenção preventiva primária objetiva impedir que dado indivíduo experimente a droga. Em geral, os programas desse tipo têm eficiência limitada e encerram-se no momento que o sujeito experimenta a droga em questão. A intervenção secundária é direcionada a indivíduos que já utilizaram a droga e tem como objetivo impedir que o indivíduo continue a usá-la, inibindo o abuso e a dependência. No caso do êxtase, essa estratégia também seria útil, porém tem suas limitações, ainda mais quando se trata de uma droga com efeitos descritos como tão prazerosos. Outro tipo de intervenção, que não exclui as outras, seria a redução de dano, em que, uma vez que o indivíduo já utiliza determinada droga, são fornecidas informações para que, se ele não puder, não quiser ou não conseguir deixar de consumi-la, que o faça com menores riscos.

Qualquer que seja a opção preventiva, é preciso ter claro que sempre haverá indivíduos que irão optar por experimentar êxtase, dos quais alguns passarão a usá-lo com alguma freqüência. A proibição, a punição e a discriminação nunca foram efetivas para o desencorajamento daqueles que escolhem usar determinada droga, o que pode ser evidenciado através de exemplos históricos como a Lei Seca nos Estados Unidos. Assim, de acordo com a estratégia da redução de dano, é importante a divulgação de informações de segurança para aqueles que utilizam ou venham a utilizar êxtase:

- beber líquido com freqüência, mas sem exagero;

- beber não apenas água, mas também sucos de frutas ou bebidas que possam repor as perdas eletrolíticas, bebidas com açúcar ou sais minerais;

- fazer um intervalo de pelo menos 6 horas entre o consumo de comprimidos de MDMA;
- quando em atividade física, na pista de dança, por exemplo, ausentar-se do local algumas vezes durante a noite para relaxar. A maioria dos clubes têm, atualmente, um lugar para relaxamento, onde a música é mais baixa e há ventilação e lugares confortáveis para sentar e descansar;

- contar a um acompanhante exatamente que drogas foram usadas, pois se houver necessidade de auxílio médico em pronto-socorro, essas informações serão muito importantes para uma intervenção clínica adequada;

- se possível, indagar sobre os efeitos do comprimido que será utilizado a quem já o utilizou, já que a composição do comprimido é sempre incerta e pode ter efeitos imprevisíveis;

- evitar ao máximo a mistura de êxtase com outras drogas psicotrópicas, em especial álcool, solventes voláteis, anfetamina, cocaína e crack;

- não utilizar êxtase como medicação para a depressão usualmente posterior ao uso de êxtase;

- fazer intervalos entre episódios de consumo, pois quanto maiores os intervalos, menor a possibilidade de problemas advindos do uso.

Por um lado, os consumidores de êxtase são favorecidos pelo risco legal mínimo do consumo e pela falta de conhecimento da população sobre essa nova droga. Por outro lado, o desconhecimento da MDMA no Brasil pode trazer problemas para usuários que tenham que recorrer a intervenções médicas em função de complicações clínicas agudas decorrentes do uso. É importante salientar que ainda há lacunas sobre o mecanismo de ação da MDMA, sobre a interação da MDMA com outras substâncias, sobre os motivos das diferenças nas reações individuais à droga e sobre as conseqüências do uso a longo prazo. Também é importante destacar que a ilegalidade é um fator que torna incerta e não fiscalizada a composição do comprimido (diga-se de passagem que há páginas na Internet que divulgam como sintetizar MDMA). Sínteses caseiras, sem a 
tecnologia adequada, podem levar a substâncias de conseqüências neurológicas perigosas e por vezes irreversíveis. Assim, a opção individual de usar êxtase comporta sempre, até o momento, um certo risco, e nesse sentido seriam adequadas e necessárias intervenções preventivas de caráter primário e secundário que, para serem efetivas, devem levar em conta as características da população consumidora e seu padrão de uso.

\section{REFERÊNCIAS}

1. Milroy CM. Ten years of 'ecstasy'. J R Soc Med 1999;92(2):68-71.

2. Rochester JA, Kirchner JT. Ecstasy (3,4methylenedioxymethamphetamine): history, neurochemistry, and toxicology. J Am Board Fam Pract 1999;12(2):137-142.

3. Laranjeira R, Dunn J, Rassi R, Fernandes M. "Extase" (3,4 metilenodioximetanfetamina, MDMA): uma droga velha e um problema novo? Revista ABP-APAL 1996; 18(3):77-81

4. Schwartz RH, Miller NS. MDMA (ecstasy) and the rave: a review. Pediatrics 1997;100(4): 705-708.

5. Panke WN, Kurland MD, Unger S, Savage C, Grof S. The experimental use of psychodelic (LSD) psychotherapy. JAMA 1970;212(11): 1856-1864.

6. Cesarotto O. Escritos de Freud sobre a cocaína-um affair freudiano. São Paulo: Iluminuras; 1989.

7. Grinspoon L, Bakalar JB. Can drugs be used to enhance the psychotherapeutic process? Am J Psychother 1986;40(3):393-404.

8. Saunders N. Ecstasy e a cultura dance. São Paulo: Publisher Brasil; 1996.

9. Cuomo MJ, Dyment PG, Gammino VM. Increasing use of "Ecstasy" (MDMA) and other hallucinogens on a college campus. J Am Coll Health 1994;42(6):271-274.

10. Peroutka SJ. Incidence of recreational use of 3,4-methylenedimethoxymethamphetamine (MDMA, "ecstasy") on an undergraduate campus [letter]. N Engl J Med 1987;317(24): 1542-1543.

11. Getting high on Ecstasy. Newsweek 1985; April 13:96.

12. A crackdown on Ecstasy. Time 1985; June 10: 64.

13. The trouble with Ecstasy. Life 1985;September: $88-94$.

14. Beck J, Morgan PA. Designer drug confusion: a focus on MDMA. J Drug Educ 1986;16(3): 287-302.

15. McClain HJ, Sapienza F. The role of abuse liability testing in drug control procedures. In: Fischman MW, Mello NK, eds. Testing for abuse liability of drugs in humans. Rockville: National Institute on Drug Abuse; 1989. [Research Monograph Series, 92]. pp. 21-42.

16. Brown ER, Jarvie DR, Simpson D. Use of drugs at 'raves'. Scot Med J 1995;40(6): 168-171.

17. Holland J. Positron emission tomography findings in heavy users of MDMA. Lancet 1999;353(9152):592

18. Cloud J. The lure of ecstasy. Time 2000 June 5 : 30-36.
19. Palomino E. Babado forte: moda, música e noite na virada do século 21. São Paulo: Mandarim; 1999.

20. Azevedo S, Kulzzynsky V. Agito sem fim. Veja São Paulo 1999 junho 14:16-18.

21. Silva A. Polícia fecha laboratório de ecstasy em São Paulo. Folha de São Paulo 2000 agosto 19:C1.

22. Cook A. Ecstasy (MDMA): alerting users to the dangers. Nurs Times 1995;91(16):32-33.

23. Calafat A, Stocco P, Mendes F, Simon J, Wijngaart G, Sureda MP, et al. Characteristics and social representation of ecstasy in Europe. Valencia: IREFREA \& European Comission/ Martin Impressores, S.L.; 1998

24. Elk C. MDMA (Ecstasy): useful information for health professionals involved in drug education programs. J Drug Educ 1996;26(4): 349-356.

25. Wolff K, Hay AW, Sherlock K, Conner M. Contents of "ecstasy" [letter]. Lancet 1995; 346(8982):1100-1101.

26. Solowij N, Hall W, Lee N. Recreational MDMA use in Sydney: a profile of 'Ecstasy' users and their experiences with the drug. $\mathrm{Br}$ J Addict 1992;87(8):1161-1172.

27. Cohen RS. Subjective reports on the effects of the MDMA ('ecstasy') experience in humans. Prog Neuropsychopharmacol Biol Psychiatry 1995;19(7):1137-1145.

28. Ferigolo M, Medeiros FB, Barros HM. "Exxtase": revisão farmacológica. Rev Saude Publica 1998;32(5):487-495.

29. Vollenweider FX, Gamma A, Liechti M, Huber T. Psychological and cardiovascular effects and short-term sequelae of MDMA ("ecstasy") in MDMA-naive healthy volunteers. Neuropsychopharmacology 1998;19(4): 241-251.

30. O'Connor B. Hazards associated with the recreational drug 'ecstasy'. Br J Hosp Med 1994;52(10):507-514.

31. McGuire PK, Cope H, Fahy TA. Diversity of psychopathology associated with use of 3,4methylenedioxymethamphetamine ('Ecstasy'). Br J Psychiatry 1994;165(3):391-395.

32. Creighton FJ, Black DL, Hyde CE. 'Ecstasy' psychosis and flashbacks. Br J Psychiatry 1991;159(Nov):713-715.

33. Grob CS, Poland RE, Chang L, Ernst T. Psychobiologic effects of 3,4-methylenedioxymethamphetamine in humans: methodological considerations and preliminary observations. Behav Brain Res 1996;73(1-2): 103-107.

34. Huether G, Zhou D, Ruther E. Causes and consequences of the loss of serotonergic presynapses elicited by the consumption of 3,4-methylenedioxymethamphetamine (MDMA, "ecstasy") and its congeners. J Neural Transm (Budapest) 1997;104(8-9): 771-794

35. Green AR, Cross AJ, Goodwin GM. Review of the pharmacology and clinical pharmacology of 3,4-methylenedioxymethamphetamine (MDMA or "Ecstasy"). Psychopharmacology (Berlin) 1995;119(3):247-260.

36. Bailly $\mathrm{D}$. Troubles neuropsychiatriques liés à la MDMA ("ecstasy"). L'Encéphale 1999;XXV: $595-602$.

37. Box SA, Prescott LF, Freestone S. Hyponatraemia at a rave. Postgrad Med J 1997; 73(855):53-54.

38. Matthai SM, Davidson DC, Sills JA, Alexandrou D. Cerebral oedema after ingestion of MDMA ("ecstasy") and unrestricted intake of water [letter]. Br Med J 1996;312(7042): 1359.

39. Schwab M, Seyringer E, Brauer RB, Hellinger A, Griese EU. Fatal MDMA intoxication [letter; comment]. Lancet 1999;353(9152): 593-594.

40. Bryden AA, Rothwell PJ, PH OR. Urinary retention with misuse of "ecstasy". Br Med J 1995;310(6978):504.

41. Whitaker-Azmitia PM, Aronson TA. "Ecstasy" (MDMA)-induced panic [letter]. Am J Psychiatry 1989;146(1):119.

42. Cohen RS. Adverse symptomatology and suicide associated with the use of methylenedioxymethamphetamine (MDMA; “Ecstasy"). Biol Psychiatry 1996;39(9):819-820.

43. Jansen KL. Ecstasy (MDMA) dependence. Drug Alcohol Depend 1999;53(2):121-124.

44. Lamb RJ, Griffiths RR. Self-injection of d,1-3,4-methylenedioxymethamphetamine (MDMA) in the baboon. Psychopharmacology (Berlin) 1987;91(3):268-272.

45. Krystal JH, Price LH, Opsahl C, Ricaurte GA, Heninger GR. Chronic 3,4-methylenedioxymethamphetamine (MDMA) use: effects on mood and neuropsychological function? Am J Drug Alcohol Abuse 1992;18(3):331-341.

46. Ricaurte GA, Markowska AL, Wenk GL, Hatzidimitriou G, Wlos J, Olton DS, 3,4Methylenedioxymethamphetamine, serotonin and memory. J Pharmacol Exp Ther 1993; 266(2):1097-1105.

47. NIDA. Popular rave drug "Ecstasy" impairs memory, apparently related to brain damage [site da Internet]. http://www.health.org/ pressrel. Acessado em 1998.

48. Spatt J, Glawar B, Mamoli B. A pure amnestic syndrome after MDMA ("ecstasy") ingestion [letter]. J Neurol Neurosurg Psychiatry 1997; 62(4):418-419. 
49. Allen RP, McCann UD, Ricaurte GA. Persistent effects of (+/-) 3,4-methylenedioxymethamphetamine (MDMA, "ecstasy") on human sleep. Sleep 1993;16(6):560-564.

50. Redfearn PJ, Agrawal N, Mair LH. An association between the regular use of 3,4 methylenedioxy-methamphetamine (ecstasy) and excessive wear of the teeth. Addiction 1998; 93(5):745-748.

51. McElhatton PR, Bateman DN, Evans C, Pughe $\mathrm{KR}$, Thomas SH. Congenital anomalies after prenatal ecstasy exposure [letter]. Lancet 1999;354(9188):1441-1442.

52. Pacifici R, Zuccaro P, Farré M, Pichini S, Di Carlo S, Roset PN, et al. Immunomodulating properties of MDMA alone and in combination with alcohol: a pilot study. Life Sci 1999; 65(26):309-316.

53. McKenna DJ, Peroutka SJ. Neurochemistry and neurotoxicity of 3,4-methylenedioxymethamphetamine (MDMA, "ecstasy"). J Neurochem 1990;54(1):14-22.

54. Rattray M. Ecstasy: towards an understanding of the biochemical basis of the actions of MDMA. Essays Biochem 1991;26:77-87.

55. Fischer HS, Zernig G, Schatz DS, Humpel C, Saria A. MDMA ("ecstasy") enhances basal acetylcholine release in brain slices of the rat striatum. Eur J Neurosci 2000;12(4): 1385-1390.

56. McCann UD, Szabo Z, Scheffel U, Dannals RF, Ricaurte GA. Positron emission tomographic evidence of toxic effect of MDMA ("Ecstasy") on brain serotonin neurons in human beings [see comments]. Lancet 1998;352(9138): 1433-1437.

57. Reed LJ, Winstock A, Cleare AJ, McGuire P. Toxic effect of MDMA on brain serotonin neurons [letter; comment]. Lancet 1999;353(9160): 1268; discussion 1270-1271.

58. Morgan JF. Toxic effect of MDMA on brain serotonin neurons [letter; comment]. Lancet 1999;353(9160):1268-1269; discussion 1270-1271.

59. Jansen KL, Forrest AR. Toxic effect of MDMA on brain serotonin neurons [letter; comment]. Lancet 1999;353(9160):1270-1271.

60. Carlini EA, Carlini-Cotrim B, Silva-Filho AR, Barbosa MTS. II Levantamento nacional sobre o uso de psicotrópicos em estudantes de $1^{\circ} \mathrm{e}$ $2^{\circ}$ graus - 1989. São Paulo: Centro Brasileiro de Informações sobre Drogas - Departamento de Psicobiologia da Escola Paulista de Medicina; 1990.

61. Carlini-Cotrim B, Carlini EA, Silva-Filho AR, Barbosa MTS. O uso de drogas psicotrópicas por estudantes de $1^{\circ}$ e $2^{\circ}$ graus da rede estadual em dez capitais brasileiras, em 1987. Consumo de drogas no Brasil em 1987. Brasília: Centro de Documentação do Ministério da Saúde; 1989

62. Galduróz JCF, D’Almeida V, Carvalho V, Carlini EA. III Levantamento sobre o uso de drogas entre estudantes de 1 o e $2^{\circ}$ graus em dez capitais brasileiras - 1993. São Paulo: Centro Brasileiro de Informações sobre Drogas Departamento de Psicobiologia da Escola Paulista de Medicina; 1994.

63. Galduróz JCF, Noto AR, Carlini EA. IV Levantamento sobre o uso de drogas entre estudantes de $1^{\circ}$ e $2^{\circ}$ graus em dez capitais brasileiras - 1997. São Paulo: Centro Brasileiro de Informações sobre Drogas-Departamento de Psicobiologia da Escola Paulista de Medicina; 1997

Manuscrito recibido em 6 de março de de 2000. Aceito em versão revisada em 10 de outubro de 2000

ABSTRACT This review focuses on 3,4-methylenedioxymethamphetamine, an illegal drug known as "ecstasy." Ecstasy was introduced in Brazil in 1994. Data are lacking on the epidemiology and usage pattern of the drug in Brazil. However, there is evidence that until now the use of ecstasy has been limited to middle-class or upper-middle-class youth, so that most people, including health care professionals, are unfamiliar with the drug. However, ecstasy may be becoming more popular in Brazil, following a pattern seen in North America and Europe. Possibly contributing to the drug's popularity is the fact that ecstasy is sold as a pill and is thus extremely easy to use. Ecstasy has a reputation for not being physically dangerous; however, there are many reports of adverse reactions associated with the drug. In addition, it is known that not all pills sold as ecstasy actually contain methylenedioxymethamphetamine. Since there is no quality control for the pills' contents, users never know exactly what they are taking. Thus, although users may perceive the effects of the drug as mostly positive, ecstasy is potentially dangerous. Primary and secondary interventions are needed to prevent the use of ecstasy and the occurrence of adverse reactions. To be effective, these measures must take into consideration the characteristics of the user population and the usage patterns. It is also essential to prepare health professionals for emergency medical interventions in cases of intoxication and complications resulting from the use of ecstasy. 